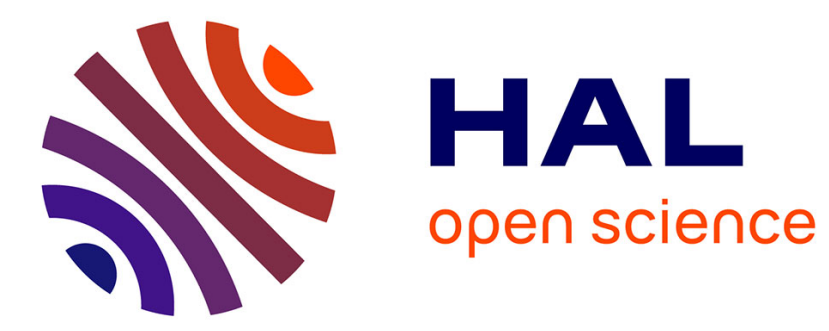

\title{
Recombination processes in Al2o3-InSb structures
}

G. Boucharlat, G. Kamarinos, P. Viktorovitch, B. Munier

\section{To cite this version:}

G. Boucharlat, G. Kamarinos, P. Viktorovitch, B. Munier. Recombination processes in Al2o3-InSb structures. Revue de Physique Appliquée, 1978, 13 (12), pp.633-635. 10.1051/rphysap:019780013012063300 . jpa-00244516

\section{HAL Id: jpa-00244516 https://hal.science/jpa-00244516}

Submitted on 1 Jan 1978

HAL is a multi-disciplinary open access archive for the deposit and dissemination of scientific research documents, whether they are published or not. The documents may come from teaching and research institutions in France or abroad, or from public or private research centers.
L'archive ouverte pluridisciplinaire HAL, est destinée au dépôt et à la diffusion de documents scientifiques de niveau recherche, publiés ou non, émanant des établissements d'enseignement et de recherche français ou étrangers, des laboratoires publics ou privés. 


\title{
RECOMBINATION PROCESSES IN $\mathrm{Al}_{2} \mathrm{O}_{3}$-InSb STRUCTURES
}

\author{
G. BOUCHARLAT $(*)$, G. KAMARINOS $(*)$, P. VIKTOROVITCH $(*)$ \\ and B. MUNIER $(* *)$
}

\begin{abstract}
Résumé. - Des structures Métal-Isolant-InSb, utilisables en imagerie infrarouge avec lecture par injection de charge ont été developpées. La sensibilité de ces dispositifs est liée aux processus de génération-recombinaison dans le semiconducteur. Diverses méthodes ont été mises en œuvre pour étudier ces processus. Les durées de vie des porteurs ont été évaluées à partir de diverses expériences : mesures de capacité transitoire en inversion ou en désertion, mesures de conductance du dispositif, mesures d'effet photomagnétoélectrique. La confrontation de ces résultats permet de conclure à l'existence d'un gradient de durée de vie des porteurs, celle-ci pouvant varier de $1 \mathrm{~ns}$ à l'interface, à 100 ns dans le volume du semiconducteur.
\end{abstract}

\begin{abstract}
Metal-Insulator-InSb structures, for infrared imaging devices operating in the charge injection mode, have been developed. The sensitivity of devices is conditioned by the generationrecombination processes occurring in the semiconductor. Several methods have been used to study these generation-recombination processes. $C(t)$ experiments in depletion and inversion regime, conductance measurements and photomagnetoelectric effects were performed on $\mathrm{Al}-\mathrm{Al}_{2} \mathrm{O}_{3}-\mathrm{n} \mathrm{InSb}$ MIS structures, in order to obtain data about recombination processes. These experimental results show a gradient in carriers lifetime which varies from $1 \mathrm{~ns}$ at the insulator-InSb interface to $100 \mathrm{~ns}$ inside the bulk of InSb.
\end{abstract}

1. Introduction. - One possible solution to obtain infrared monolithic focal plane arrays is to make high quality MIS structures on narrow-gap semiconductors. InSb has been studied for detection in the 3-5 $\mu \mathrm{m}$ atmospheric window. Several types of InSb MIS structures have been studied, using various dielectric materials : anodic oxide [1,2], chemical vapour deposed (C.V.D.) $\mathrm{SiON}$ or $\mathrm{SiO}_{2}[3,4]$, evaporated $\mathrm{SiO}_{2}$ or $\mathrm{Al}_{2} \mathrm{O}_{3}$ [5].

In this contribution, we study the electrical properties of $\mathrm{Al}-\mathrm{Al}_{2} \mathrm{O}_{3}-\mathrm{n} \mathrm{InSb}$ structures at $77 \mathrm{~K} . \mathrm{Al}_{2} \mathrm{O}_{3}$ is chosen for its high permittivity $\left(\varepsilon_{\mathrm{r}}=8\right)$ and its high breakdown field strength

$$
\left(E_{\mathrm{c}}>4 \times 10^{6} \mathrm{~V} \cdot \mathrm{cm}^{-1}\right) \text {. }
$$

Furthermore it is easily obtained by electron beam deposition. In order to achieve highly sensitive devices, it is necessary first to understand and then to reduce the generation-recombination (G-R) processes occurring at or near the insulator-semiconductor interface.

Several electrical characterization methods have been used, in order to obtain the lifetime in InSb; each method provides the carriers lifetime corresponding to a particular region of the semiconductor. Measurements were carried out on $\mathrm{Al}_{-}-\mathrm{Al}_{2} \mathrm{O}_{3}-\mathrm{InSb}$ MIS structures. Donors concentrations are in the range of $10^{14}-10^{15} \mathrm{~cm}^{-3}$. Crystals are low-dislocated $\left(\right.$ E.P.D. $\left.<100 \mathrm{~cm}^{-2}\right)$. Slab shaped samples were

$\left(^{*}\right)$ Laboratoire « Physique des Composants à Semiconducteurs » ENSERG, 23, av. des Martyrs, 38031 Grenoble Cedex, France.

$\left({ }^{* *}\right)$ Thomson-CSF, Division Tubes Electroniques, 38120 StEgrève, France. mecanochemically polished and then etched in a nitric-lactic solution [6]. $\mathrm{Al}_{2} \mathrm{O}_{3}$ and aluminium dots are electron beam evaporated. The shape of the dots is obtained by a mechanical mask or photoresist technique. The devices are mounted in a liquid- $\mathrm{N}_{2}$ cooled deward $(77 \mathrm{~K})$. In this paper, we analyse the G-R processes in an $\mathrm{Al}_{2} \mathrm{O}_{3}$-InSb structure.

\section{Experimental characterization of G-R processes.}

- 2.1 CONDUCTANCE MEASUREMENTS. - This measurement is performed on devices biased in the strong inversion mode. In these conditions, the MIS structure can be represented by the equivalent electrical circuit shown in figure $1: C_{\mathrm{i}}$, the insulator capacitance, is in series with the parallel combination of $C_{\mathrm{D}}$ and $G_{\mathrm{g}}$, which are the capacitance and the conductance of the space-charge region in the semiconductor. $G_{\mathrm{g}}$ symbolizes the generation in the space-charge region, and can be calculated from the maximum value of the ratio $G_{\mathrm{m}} / \omega$, where $G_{\mathrm{m}}$ is the conductance and $\omega$ the frequency. This maximum occurs for $\omega=\omega_{\mathrm{M}}$ :

$$
G_{\mathrm{g}}=\frac{C_{\mathrm{i}}^{2} \omega_{\mathrm{M}}}{2\left(\frac{G_{\mathrm{m}}}{\omega}\right)_{\mathrm{Max}}} .
$$

Using the Shockley-Hall-Read (SHR) model of G-R processes [7], we deduce the carriers lifetime in the steady state space-charge region :

$$
\tau=\frac{\mathrm{n}_{\mathrm{i}}}{2 N_{\mathrm{d}}} \frac{1}{\omega_{\mathrm{M}}}\left(1-\frac{C_{\mathrm{i}} \omega_{\mathrm{M}}}{G_{\mathrm{g}}}\right)
$$




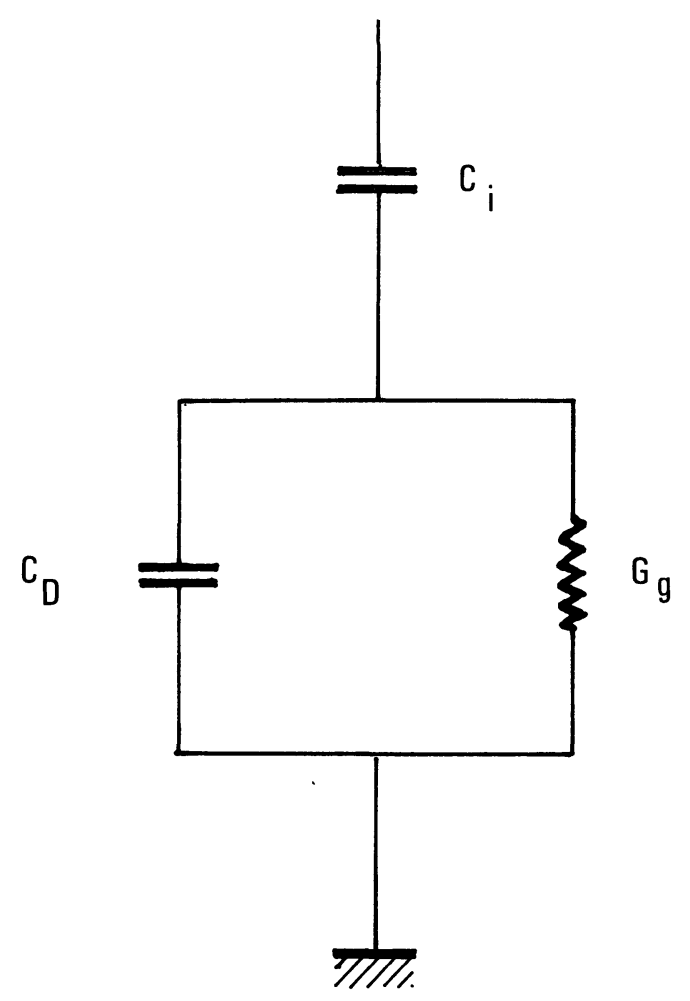

FIG. 1. - Simple equivalent electrical circuit of the MIS structure under strong inversion bias.

The conductance $G_{\mathrm{m}}$ is measured with a PAR 124 lock-in amplifier. A typical $G_{\mathrm{m}} / \omega$ curve versus frequency is shown in figure 2 .

G-R processes are due to trap-centers energetically located around the intrinsic level in the forbidden gap, and spatially around the crossing of the intrinsic level with the Fermi-level (Fig. 3). Therefore G-R processes mainly occur at a mean distance $w$ from the surface :

$$
w=\sqrt{\frac{4 \varepsilon \varphi_{\mathrm{B}}}{q N_{\mathrm{d}}}}-\sqrt{\frac{2 \varepsilon \varphi_{\mathrm{B}}}{q N_{\mathrm{d}}}}
$$

which gives $w=0.25 \mu \mathrm{m}$.

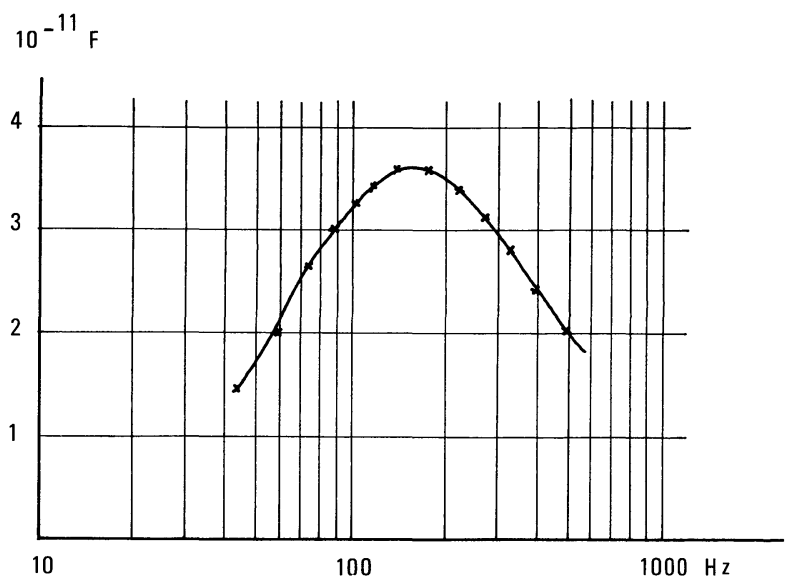

Fig. 2. $-G_{m} / \omega$ versus frequency for n-type InSb MIS structure measured in the strong inversion regime.

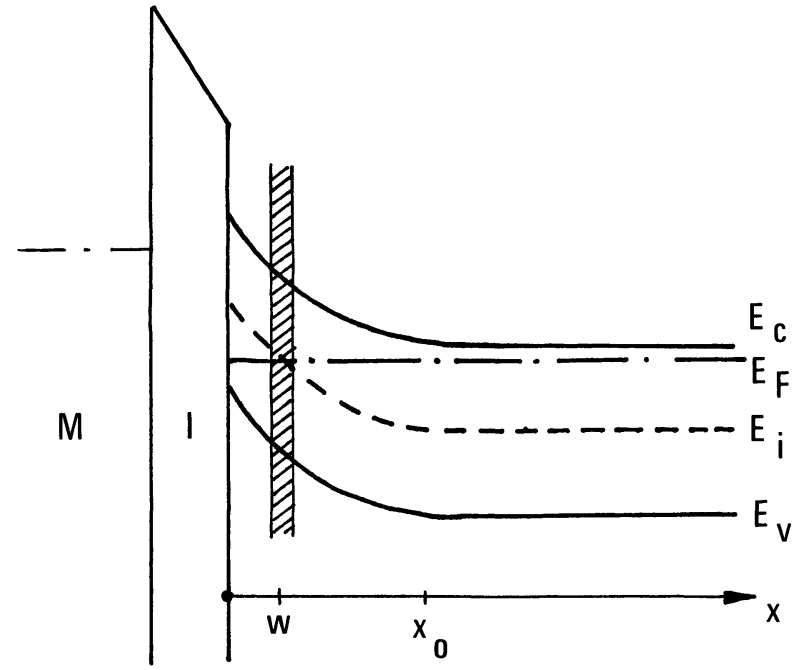

FIg. 3. - Bands diagram in a MIS structure in the strong inversion regime. $W:$ depth of efficient generation.

The lifetime measured with this technique is about 1 ns.

2.2 Transient Capacitance measurements. Lifetime in semiconductor is easily obtained by transient capacitance measurements. A depleting voltage step is applied to the Al-electrode of the structure, initially biased in the inversion regime. The spacecharge region is suddenly extended and relaxes to its equilibrium value. The time constant $T$ of this relaxation is simply connected with the lifetime $\tau$ :

$$
T=2 \tau \frac{N_{\mathrm{d}}}{n_{\mathrm{i}}} \frac{C_{\mathrm{D}}+C_{\mathrm{i}}}{C_{\mathrm{D}}}
$$

with the hypothesis of SHR G-R centers in the middle of the forbidden gap.

Simmons and Wei [8] have shown that, in the pulsed MIS capacitor, generation processes occur in the thickness $X_{\mathrm{d}}-X_{0}$ of the depleted region $\left(X_{\mathrm{d}}=\right.$ depletion width as a function of time ; $X_{0}=$ depletion width at equilibrium).

The experimental value of the MIS capacitance is determined by measuring the alternative H.F. current through the structure. The retention time is $20 \mathrm{~ms}$, with a step voltage of $-5 \mathrm{~V}$ applied on the Al-gate. The lifetime deduced from this measurement is about $10 \mathrm{~ns}$. According to Simmons and Wei [8], this value is a figure of the average lifetime on the thickness $X_{\mathrm{d}}-X_{0}$, which is about $3.6 \mu \mathrm{m}$ (Fig. 4).

Identical retention time values are obtained when the structure is initially biased in depletion regime. Now, in such experimental conditions, surface generation occurs. Therefore this contribution seems negligeable. Besides, this is confirmed by the fact that various chemical surface treatments before $\mathrm{Al}_{2} \mathrm{O}_{3}$ deposition do not modify the response time. 


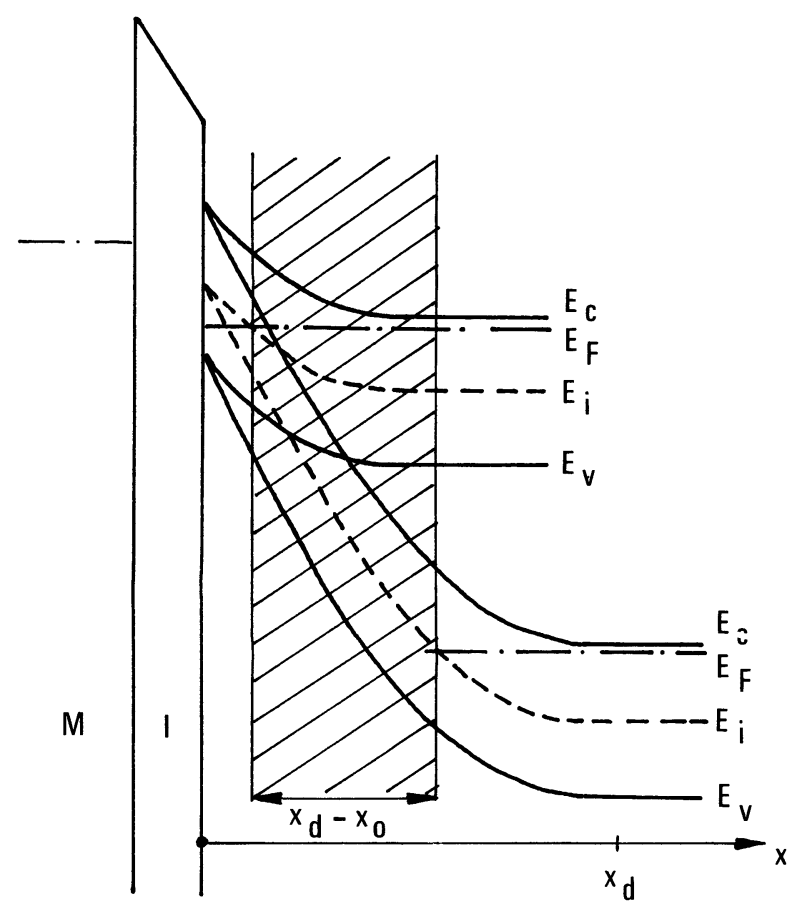

Fig. 4. - Bands diagram in a MIS structure under a deep depletion bias. $X_{\mathrm{d}}-X_{0}$ : width of efficient generation. (After Simmons and Wei [8].)

2.3 Voltage SWEEP CAPACITANCE MEASUREMENTS. - We now apply a depleting voltage sweep $V_{\mathrm{G}}(t)$ to a MIS structure initially biased in deep depletion regime. A sweep rate $\alpha$ can be chosen in order to have a constant depletion width $X_{\mathrm{d}}>X_{0}$. In this steadystate condition, the depletion width is large enough to supply all the charge needed by the increasing gate voltage. The quasi-equilibrium condition is written [9] :

$$
\alpha C_{\mathrm{i}}=q g\left(X_{\mathrm{d}}-X_{0}\right)
$$

where $g$ is the generation rate in the space-charge region. With the same SHR hypothesis previously used, we can obtain the lifetime $\tau$ in the space-charge region. Our measurements give a lifetime $\tau=10 \mathrm{~ns}$. This value is the same as the one determined by transient capacitance experiment. As a matter of fact, these two types of measurements are related to the same region of the semiconductor.
2.4 PME EFFECT MEASUREMENTS. - PME effect measurements on semiconductor slabs provide the bulk lifetime and the surface recombination rate [10]. The determination of this latter parameter requires a slab thickness on the order of the ambipolar diffusion length of carriers, which is very small (about $10 \mu \mathrm{m}$ ). Measurements were performed only on thick slabs $(600 \mu \mathrm{m})$, and provided only the bulk-lifetime; the measured values are included between 50 and $100 \mathrm{~ns}$.

3. Discussion. - All measurements are summarized in the table I :

\section{TABLE I}

\begin{tabular}{|c|c|c|}
\hline Measurement & Depth & Lifetime \\
\hline Conductance & $0.25 \mu \mathrm{m}$ & $1 \mathrm{~ns}$ \\
\hline Transient capacitance & $3.6 \mu \mathrm{m}$ & $10 \mathrm{~ns}$ \\
\hline Voltage sweep capacitance & $3 \mu \mathrm{m}$ & $10 \mathrm{~ns}$ \\
\hline PME current & volume & 50 to $100 \mathrm{~ns}$ \\
\hline
\end{tabular}

These three kinds of experiments provide the gradient of the bulk mean lifetime from the $\mathrm{Al}_{2} \mathrm{O}_{3}$ InSb interface toward the bulk of the semiconductor. The observed increase of the mean lifetime when going away from the semiconductor surface suggests that the material is disturbed near the surface. The thickness of this disturbed layer is then approximately a few tenths of $\mu \mathrm{m}$.

4. Conclusion. - Several methods of MIS electrical characterization have been used in order to determine the mean carriers lifetime in the semiconductor. Each method provides a value related to a particular depth in the semiconductor.

These experiments, performed on $\mathrm{Al}_{2} \mathrm{O}_{3}$-InSb MIS structures, show an increasing mean lifetime when going away from the semiconductor surface to the bulk. Moreover the generation-recombination processes are not dominated by the interface states.

All these results suggest that the generation-recombination processes are related to states located in a layer of a few tenths of $\mu \mathrm{m}$ thick under the semiconductor surface.

\section{References}

[1] Pagnia, H., Phys. Lett. 51A (1975) 389.

[2] Etchells, A., Fisher, C. W., J. Appl. Phys. 47 (1976) 4605.

[3] Margalit, S. et al., J. Appl. Phys. 46 (1975) 3999.

[4] KIM, J. C., IEEE Trans. on PHP 10 (1974).

[5] Тном, R. D. et al., Intern. Conf. on CCD, San Diego (1975).

[6] Brennan, L. C., Gri, N. J., J. Electrochem. Soc. 117 (1970) 391.
[7] Shockley, W., Read, W. T., Phys. Rev. 87 (1952) 835.

[8] Simmons, J. G., WeI, L. S., Solid State Electron. 19 (1976) 153.

[9] Board, K., Simmons, J. G., Solid State Electron. 20 (1977) 859.

[10] Kurnick, S. N., Zitter, R. N., J. Appl. Phys. 27 (1956) 278. 